\title{
PENERAPAN MODIFIKASI MEDIA KARDUS DALAM MENINGKATKAN PEMBELAJARAN LOMPAT JAUH PADA SISWA SEKOLAH DASAR
}

\section{HELDIE BRAMANTHA MUFARRAHATUS SYARIFAH}

Universitas Abdurachman Saleh Situbondo e-mail: Heldiebramantha86@gmail.com

\begin{abstract}
ABSTRAK
Penelitian ini dilatar belakangi rendahnya keaktifan dan gerak dasar lompat dalam pembelajaran lompat jauh. Penelitian ini bertujuan untuk mengetahui peningkatan pembelajaran pendidikan jasmani materi pokok lompat jauh dengan menggunakan media kardus pada siswa kelas IV Sekolah Dasar Negeri 3 Mangaran Kecamatan Mangaran Kabupaten Situbondo. Penelitian ini merupakan penelitian tindakan kelas. Subjek dalam penelitian ini adalah siswa kelas IV di SDN 3 Mangaran Kecamatan Mangaran Kabupaten situbondo dengan jumlah total 14 siswa. Instrumen yang digunakan yaitu proses lompat jauh. Teknik analisis data yang digunakan dalam penelitian ini adalah deskriptif kualitatif dan kuantitatif. Hasil Penelitian menunjukkan bahwa siswa lebih antusias, aktif, tidak malas, dan merasa senang. Sedangkan nilai kuantitatif dapat dilihat dari hasil tes unjuk kerja teknik dasar lompat jauh, nilai rerata siswa siklus I pertemuan pertama 69,9 dan siswa yang mencapai KKM (Kriteria Ketuntasan Minimal) 64,3 dari ketentuan sekolah yaitu 70. Pada kedua meningka menjadi 78,9 dan siswa yang mencapai KKM (Kriteria Ketuntasan Minimal) 88,1. Hasil ini sangat meningkat dibandingkan dengan hasil tes unjuk kerja siswa kelas IV pra siklus yang dapat dilihat dari hasil tes unjuk. kerja teknik dasar lompat jauh nilai reratanya 67,8 dan siswa yang mencapai KKM hanya 52\% tuntas dari ketentuan KKM sekolah yaitu 70. Media kardus dapat mendorong siswa lebih aktif serta lebih merangsang siswa dalam menguasai gerak lompat jauh, pada pembelajaran gerak dasar lompat jauh. Pembelajaran menarik minat, semangat dan partisipasi siswa untuk menguasai gerak dasar lompat jauh. dan partisipasi siswa untuk menguasai gerak dasar lompat jauh.
\end{abstract}

Kata kunci: pembelajaran lompat jauh, alat bantu, kardus

\section{PENDAHULUAN}

Atletik merupakan cabang olahraga tertua di dunia dan sering disebut juga induk dari semua cabang olahraga. Hal ini disebabkan karena gerakan atletik sudah tercermin pada manusia purba. Secara tidak langsung gerakannya sudah mereka lakukan pada kehidupan sehari-hari yaitu seperti dalam mempertahankan hidup, mengembangkan hidup, dan dalam usaha menyelamatkan diri dari suatu gangguan. Dalam atletik terdapat nomor olahraga yaitu jalan, lari, lompat, dan lempar.

Lompat jauh adalah suatu gerakan mengangkat tubuh dari suatu 
titik ke titik lain yang lebih jauh dengan ancang-ancang lari cepat atau lambat dengan menumpu satu kaki dan mendarat dengan kaki/anggota tubuh lainnya dengan keseimbangan yang baik

Salah satu masalah menarik dalam peningkatan lompat jauh adalah menyangkut metode pembelajarannya. Metode pembelajaran yang digunakan sangat berpengaruh terhadap hasil yang dicapai. Dalam praktik pembelajaran lompat jauh di sekolah, umumnya guru hanya menekankan pada pencapaian hasil, tanpa berusaha memperbaiki metode dan proses pembelajarannya. Dalam pembelajaran teknik lompat jauh yang dilakukan para guru pendidikan jasmani di sekolah pelaksanaannya hanya ke lapangan, lalu siswa diberikan materi teknik lompat jauh, kemudian siswa disuruh mempraktikkan secara berulangulang dan diukur hasilnya. Tetapi model pembelajaran seperti itu seringkali tidak menarik dan membosankan, sehingga siswa malas mempelajari geraknya sehingga hasilnyapun menjadi kurang optimal.

Metode yang digunakan akan berpengaruh pada kualitas hasil lompatan yang akan diraih. Selama ini guru hanya berkutat pada hasil lompatan bukan pada proses. Terlebih dalam pelaksanaan pembelajaran, guru cenderung memberikan materi cara melakukan lompat jauh tanpa memberikan metode yang baik dan benar. Kemudian siswa diminta untuk mempraktekan, dilakukan pengukuran hasil lompatan, dan selesai.

Dalam pembelajaran lompat jauh guru hendaknya menggunakan media yang dapat membantu siswa mengatasi masalah hasil lompatan yang datar. Media yang digunakan hendaknya aman, tidak menyebabkan cedera, mudah di dapat, dan dapat menarik perhatian siswa serta memacu siswa untuk bergerak.

Dalam hal ini, peneliti memillih Kardus sebagai media dalam kegiatan belajar mengajar lompat jauh. Kardus merupakan media yang dapat dimanfaatkan atau digunakan memperbaiki tolakan. Dalam penelitian tindakan kelas ini akan difokuskan pada penggunaan kardus sebagai media tolakan dengan berbagai bentuk susunan kardus. Bentuk susunan kardus ini diharapkan mampu mendorong lompatan yang tinggi dan jarak lompat yang jauh.

Kardus adalah media yang dapat dimanfaatkan atau dipakai . Alat tersebut merupakan alat visual sederhana, yang sangat penting dan murah, mudah di dapat atau bahkan dibuat sendiri. Dengan memanfaatkan media kardus tersebut diharapkan dapat menarik siswa sehingga secara tidak langsung juga memperbaiki ketrampilan siswa dalam lompat jauh

teknik dasar lompat jauh ada 4, yaitu: 1) Awalan: adalah gerakan permulaan dalam usaha untuk mendapatkan kecepatan pada waktu akan melakukan tolakan. 2) Tolakan atau tumpuan: adalah perubahan atau perpindahan gerak dari gerakan horizontal ke gerakan vertical yang dilakukan secara cepat. 3) Sikap badan di udara: sikap ini berkaitan dengan angin ketika badan berada di udara dan hal ini dapat mempengaruhi kecepatan dan jarak yang ditempuh. 4) Sikap Mendarat : gerakan ini merupakan gerakan inti, jangan sampai karena gerakan 
kurang tepat dapat berakibat jarak tempuh kurang maksimal.

Dengan menggunakan kardus sebagai media pembelajaran lompat jauh yang dimodifikasi secara sederhana merupakan salah satu alternatif pendekatan pembelajaran pendidikan jasmani yang dilaksanakan dengan berbagai pertimbangan, menurut Ngasmain Supartono (2007) bahwa alasan utama dari modifikasi adalah :

a. Anak bukanlah orang dewasa dalam bentuk kecil, kematangan fisik dan mental anak belum selengkap orang dewasa.

b. Pendekatan pembelajaran pendidikan jasmani selama ini kurang efektif, hanya bersifat lateral dan monoton.

c. Sarana dan prasarana pembelajaran pendidikan jasmani yang ada sekarang, hampir semuanya di desain untuk orang dewasa.

Pelaksanaan penelitian ini menggunakan alat bantu kardus yang bertujuan untuk merangsang siswa melakukan lompatan. Kardus yang dimaksud adalah bekas kemasan air minum mineral (aqua gelas) atau dengan kata lain peneliti memanfaatkan barang bekas dan peralatan sederhana sebagai alat bantu pembelajaran lompat jauh. Pembelajaran lompat jauh menggunakan kardus bertujuan agar dapat merangsang siswa untuk melakukan lompatan agar badan terangkat ke atas depan. Kardus bersifat lunak, tidak berbahaya apabila dipergunakan sebagai media pembelajaran, sehingga anak tidak merasa takut untuk melakukan latihan melompat

Pelaksanaan pembelajaran lompat jauh menggunakan alat bantu kardus yang diletakkan dengan ketinggian antara 30-50 $\mathrm{cm}$ dan diatur dengan jarak 6-8 meter. Siswa melakukan lompatan melewati kardus menggunakan awalan dengan jarak yang pendek, mendarat dengan kaki depan/ayun dan menggunakan suatu irama lari tiga langkah. (Eddy Purnomo \& Dapan: 2011- 99).

\section{METODE}

Lokasi Penelitian adalah SD Negeri 3 Mangaran Kecamatan Mangaran Kabupaten Situbondo Provinsi Jawa Timur. Penelitian ini merupakan Penelitian Tindakan Kelas (PTK) atau Classroom Action Research (CAR) yang dilakukan secara kolaboratif dan partisipatif (Wiriaatmdja, 2009: 83) Artinya peneliti tidak melakukan penelitian sendiri, namun berkolaborasi atau kerja sama dengan kolaborator dan siswa kelas IV SD Negeri 3 Mangaran Kabupaten Situbondo Secara partisipasi, peneliti bersamasama dengan mitra peneliti akan melaksanakan penelitian ini langkah demi langkah Menurut Rochiati Wiriatmadja, (2009: 13) penelitian tindakan adalah bagaimana guru dapat mengorganisasikan kondisi pembelajaran dan belajar dari pengalamannya sendiri

Desain penelitian ini menggunakan model spiral dari Kemmis dan Taggart seperti yang dikutip oleh Wiriaatmadja dalam bukunya yang berjudul Metode Penelitian Tindakan Kelas (2009: 66) yang menggambarkan penelitian kelas dilaksanakan dalam setiap langkah atau siklus terdiri dari 4 tahapan, yaitu plan (perencanaan), act (pelaksanaan), observe (pengamatan) dan reflect (refleksi).

Pengumpulan data yang diperlukan dalam penelitian tindakan kelas ini berupa catatan tentang hasil 
pengamatan. Hasil pengamatan tersebut dikumpulkan melalui pengamatan (data observasi) dan hasil tes siswa (tes unjuk kerja).

\section{HASIL DAN PEMBAHASAN}

Berdasarkan hasil observasi siklus 1 pada aktivitas siswa dapat dijelaskan bahwa sebelum proses pembelajaran dimulai, siswa ikut membantu dalam menyiapkan peralatan pembelajaran yang diperlukan. Siswa selalu memperhatikan proses pembelajaran dengan tertib, mengikuti pemanasan, kegiatan ini dan pendinginan. Dalam kegiatan inti pembelajaran siswa juga tampak aktif mengikuti proses pembelajaran

Hasil evaluasi pada siklus 1 dari kolaborator 1 dengan nilai tertinggi yaitu 81 dan nilai terendah yaitu 56, nilai rata-rata 69,9. Peserta didik yang memperoleh nilai mencapai nilai KKM terdapat $8(57,2$ $\%)$ anak, sedangkan yang belum mencapai KKM ada $6(42,8 \%)$ anak.

Data hasil evaluasi siklus 1 dari kolabolator 2 dengan nilai tertinggi 81 dan nilai terendah 56, nilai rata-rata 69 . Peserta didik yang mencapai nilai KKM terdapat $8(57,2$ $\%)$ anak, sedangkan yang belum mencapai KKM terdapat $6(42,8 \%)$ anak.

Sedangkan hasil evaluasi dari peneliti yaitu, nilai tertinggi 87 dan nilai terendah 56 dengan nilai ratarata 70,7. Peserta didik yang mencapai nilai KKM terdapat 11 ( $78,5 \%$ ) anak, sedangkan yang belum mencapai nilai KKM 3 ( $21,5 \%)$ anak. Hasil rata-rata ketuntasan dari kolabolator 1, kolabolator 2 dan peneliti sendiri adalah $69,9 \%$ tuntas.
Berdasarkan hasil observasi dari peneliti dan kolaborator, menyimpulkan bahwa selama pembelajaran siklus I sudah terlihat baik dalam perhatian, keaktifan maupun ketekunan. Ini dapat dilihat dengan antusias para siswa dalam mengikuti pembelajaran dari awal sampai akhir. Kalaupun terdapat siswa yang kurang memperhatikan serta kurang antusias itu hanya beberapa anak saja

Dengan perhatian, keaktifan, dan ketekunan siswa selama pembelajaran berlangsung berpengaruh terhadap hasil evaluasi. Adapun hasil penilaian unjuk kerja adalah 69,9\% siswa tuntas dari KKM yang telah ditentukan yaitu 70 .

Tabel 1. Hasil Siklus I

\begin{tabular}{clcccc}
\hline No & \multicolumn{1}{c}{ Kriteria } & \multicolumn{3}{c}{ Kolaborator } & $\begin{array}{c}\text { Rata- } \\
\text { rata }\end{array}$ \\
\cline { 3 - 5 } & 1 & 2 & $\begin{array}{c}\text { Pene } \\
\text { liti }\end{array}$ & \\
\hline $\mathbf{1}$ & Nilai tertinggi & 81 & 81 & 87 & 83 \\
\hline $\mathbf{2}$ & Nilai terendah & 56 & 56 & 56 & 56 \\
\hline $\mathbf{3}$ & Rata-rata & 69,9 & 69 & 70,7 & 69,9 \\
\hline $\mathbf{4}$ & Tuntas & 8 & 8 & 11 & 9 \\
\hline $\mathbf{5}$ & Belum tuntas & 6 & 6 & 3 & 5 \\
\hline $\mathbf{6}$ & Persentase tuntas & 57,2 & 57,2 & 78,5 & 64,3 \\
\hline $\mathbf{7}$ & $\begin{array}{l}\text { Persentase belum } \\
\text { tuntas }\end{array}$ & 42,8 & 42,8 & 21,5 & 35,7 \\
\hline
\end{tabular}

Hasil observasi siklus 2 pada aktivitas siswa dapat dijelaskan bahwa sebelum proses pembelajaran dimulai, siswa ikut membantu dalam menyiapkan peralatan pembelajaran yang diperlukan. Siswa selalu memperhatikan proses pembelajaran dengan tertib, mengikuti pemanasan, kegiatan ini dan pendinginan. Dalam kegiatan inti pembelajaran siswa juga tampak aktif mengikuti proses pembelajaran.

data hasil evaluasi pada siklus 2 dari kolaborator 1dengan nilai tertinggi yaitu 94 dan nilai terendah yaitu 62, nilai rata-rata 76,8. Peserta didik yang memperoleh nilai mencapai nilai KKM terdapat 
$12(85,7 \%)$ anak, sedangkan yang belum mencapai KKM ada $2(14,3$ $\%)$ anak.

Data hasil evaluasi dari kolabolator 2 dengan nilai tertinggi 100 dan nilai terendah 68 , nilai ratarata 79,2. Peserta didik yang mencapai nilai KKM terdapat 12 $(85,7 \%)$ anak, sedangkan yang belum mencapai KKM terdapat 2 $(14,3 \%)$ anak.

Sedangkan hasil evaluasi dari peneliti yaitu, nilai tertinggi 100 dan nilai terendah 68 dengan nilai ratarata 80,6. Peserta didik yang mencapai nilai KKM terdapat 13 ( $92,8 \%$ ) anak, sedangkan yang belum mencapai nilai KKM 1 ( 7,2 \%) anak. Hasil rata-rata ketuntasan dari kolabolator 1, kolabolator 2 dan peneliti sendiri adalah 78,9\% tuntas. sehingga pada siklus II ini mendapatkan hasil lebih dari yang ditargetkan peneliti yaitu tingkat ketuntasan dari $67,8 \%$ menjadi $78,9 \%$.

Tabel 2. Hasil Siklus I

\begin{tabular}{clcccc}
\hline No & \multicolumn{1}{c}{ Kriteria } & \multicolumn{3}{c}{ Kolaborator } & $\begin{array}{c}\text { Rata- } \\
\text { rata }\end{array}$ \\
\cline { 3 - 5 } & 1 & 2 & $\begin{array}{c}\text { Pene } \\
\text { liti }\end{array}$ & \\
\hline $\mathbf{1}$ & Nilai tertinggi & 81 & 81 & 87 & 83 \\
\hline $\mathbf{2}$ & Nilai terendah & 56 & 56 & 56 & 56 \\
\hline $\mathbf{3}$ & Rata-rata & 69,9 & 69 & 70,7 & 69,9 \\
\hline $\mathbf{4}$ & Tuntas & 8 & 8 & 11 & 9 \\
\hline $\mathbf{5}$ & Belum tuntas & 6 & 6 & 3 & 5 \\
\hline $\mathbf{6}$ & Persentase tuntas & 57,2 & 57,2 & 78,5 & 64,3 \\
\hline $\mathbf{7}$ & $\begin{array}{l}\text { Persentase belum } \\
\text { tuntas }\end{array}$ & 42,8 & 42,8 & 21,5 & 35,7 \\
\hline
\end{tabular}

\section{KESIMPULAN}

Dengan demikian penelitian tindakan kelas ini tidak dilanjutkan ke siklus berikutnya karena sudah berhasil.

Setelah selesai tindakan sampai akhir proses pembelajaran pada siklus I pertemuan ke-2, peneliti dan kolaborator mendiskusikan hasil observasi. Dengan adanya tindakan penelitian ini dapat meningkatkan gairah dan semangat siswa untuk mengikuti proses pembelajaran lompat jauh.

Berdasarkan hasil observasi dari peneliti dan kolaborator menyimpulkan bahwa selama pembelajaran siklus I pertemuan ke2 sudah terlihat baik dalam perhatian, keaktifan maupun ketekunan. Ini dapat dilihat dengan antusias para siswa dalam mengikuti pembelajaran dari awal sampai akhir. Kalaupun terdapat siswa yang kurang memperhatikan serta kurang antusias itu hanya beberapa anak saja.

Pada siklus 2, peserta didik lebih memperhatikan proses pembelajaran, merasa tidak terpaksa. senang, antusias, tidak malas dan lebih aktif dalam mengikuti pembelajaran dengan alat bantu kardus. Dengan semangat yang tinggi pula peserta didik melaksanakan evaluasi dengan sangat baik, sehingga target $75 \%$ tuntas mudah terwujud, bahkan lebih dari itu karena dapat mencapai $78,9 \%$ tuntas dari KKM yang telah ditentukan yaitu 70 .

Dari penjelasan kegiatan di atas menunjukkan bahwa hasil observasi dan hasil belajar peserta didik dalam pembelajaran lompat jauh dari siklus I dan siklus II ada peningkatan yang baik, selain itu dorongan kepada peserta didik dalam mengikuti kegiatan pembelajaran yang baru, membuat peserta didik merasa termotivasi untuk bisa melakukan gerak dasar lompat jauh dengan teknik yang benar. Berdasarkan hasil tersebut peneliti dan kolaborator sepakat bahwa proses pembelajaran lompat jauh dengan alat bantu kardus dapat dijadikan salah satu pendekatan pembelajaran atletik untuk kelas IV 
Jurnal Kejaora, Volume 2 Nomor 2, 2017, ISSN 2541-5042

SD Negeri 3 Mangaran Kecamatan Mangaran Kabupaten Situbondo.

\section{DAFTAR PUSTAKA}

Arikunto dan Supardi. 2011. Penelitian Tinadakan Kelas. Jakarta:Bumi Aksara

Djumidar. (2007). Dasar-Dasar Atletik. Jakarta:

Depdikbud RI. Dirjen Dikti Proyek Pembinaan Tenaga Kependidikan.

Edi, P dan Dapan. 2011. Dasar-dasar Gerak Atletik. Yogyakarta: Alfamedia

Rochiati, W. 2009. Metode Penelitian Tindakan Kelas. Jakarta: PT Remaja Rosdakarya

Lutan, L. 2000. Gerak Dasar Atletik.Jakarta: Pioner Jaya Putra.

Tim Penjas SD. 2007. Pendidikan Jasmani Olahraga dan Kesehatan SD Kelas $V$. Jakarta : Yudistira 